\title{
Teaching English Idioms as Metaphors through Cognitive-Oriented Methods: A Case in an EFL Writing Class
}

\author{
Yi-chen Chen $^{1} \&$ Huei-ling Lai ${ }^{2}$ \\ ${ }^{1}$ Department of Foreign Languages and Applied Linguistics, Yuan Ze University, Taiwan \\ ${ }^{2}$ Department of English, National Chengchi University, Taiwan \\ Correspondence: Yi-chen Chen, Department of Foreign Languages and Applied Linguistics, Yuan Ze University, \\ 135 Yuan-Tung Road, Chung-Li, Taiwan 32003, R.O.C. Tel: 886-3-463-8800. E-mail: yicc@saturn.yzu.edu.tw
}

\author{
Received: March 13, 2013 Accepted: April 8, 2013 Online Published: May 8, 2013 \\ doi:10.5539/elt.v6n6p13 URL: http://dx.doi.org/10.5539/elt.v6n6p13
}

\begin{abstract}
Idioms have long been regarded as problematic for L2 learners due to the arbitrariness of their meanings and forms. Traditional methods of teaching idioms focus on rote learning and memorization. Recent developments in cognitive linguistics research have considered idioms as analyzable expressions which are motivated by conceptual metaphors and whose meanings can derive from associations between source and target concepts. Believed to be imageable and comprehensive, idioms should be learned through the process of raising L2 learners' awareness of conceptual metaphors behind these expressions. Nevertheless, these methods fail to notice culture entailments embedded in conceptual metaphors. Especially for FL learners who share neither common cultural background nor living environment with the target language users, difficulties resulting from transferability between L1 and L2 idioms owing to cultural similarities and differences may be serious. To bridge the gap between idioms and conceptual metaphors caused by cross-cultural differences, this study suggests a teaching method by incorporating the idea of metaphoric mappings. A case study was conducted in an EFL writing class to investigate the effect of the methods. Essays written by the students before and after the instruction were analyzed. Results showed that the students increased frequencies of using not only common idiomatic expressions but also creative analogies comprising vivid images based on the conceptual metaphors taught. Additionally, they used L2 expressions whose conceptual metaphors also existed in L1 more often then expressions whose conceptual metaphors were exclusive in L2. Such findings affirm the importance of culture and provide valuable insight to EFL teachers in adopting cognitive-oriented method to teach English idioms.
\end{abstract}

Keywords: idioms, metaphors, conceptual metaphors, metaphoric mappings, EFL

\section{Introduction}

An idiom, or idiomatic expression, according to the Oxford English Dictionary, is a group of words whose meaning cannot be deduced from the individual words that form it. In other words, idioms are considered as fixed chunks with arbitrary meanings. For example, the idiom kick the bucket cannot be interpreted by simply connecting the meanings of each single word; L2 learners who want to obtain the meaning of the idiom have to memorize its corresponding figurative interpretation, which is to die. Meanings of idioms are arbitrary and thus unpredictable. Even native speakers consider learning and understanding idiomatic expressions difficult (Gibbs 1994), let alone L2 learners whose comprehension of idioms is blocked by their limited language proficiency and cultural immersion. Idioms, therefore, have been considered an obstacle for L2 learners (Kövecses \& Szabó 1996). However, idiomatic expressions are used so widely and commonly in spoken and written English that L2 learners have to prepare themselves to meet the challenge of learning and understanding them (Cooper 1999). Thus, teaching idioms to L2 learners is a necessary element in the field of EFL teaching.

Traditional methods of teahing English idioms focus on rote learning and memrozation. Such rigid learning process might be time- and effort-consuming, as learners picked up idioms discretely without associations between forms and meanings. With the advance development in research of cognitive linguistics, ways of teaching idiomatic epxressions have shifted to the idea of raising learners' awareness of conceptual metaphor, the underlying motivation behind idioms. Yet, for EFL learners who have less exposure to the target-labguage environment, a possible learning difficulty may occur due to their unfamiliarity of cultural conventions which are embedded in conceptual metaphors. To bridge the methodological and pedagogical gaps, an alternative 
method which integrates metaphoric mappings in the learning learning process is proposed. It is believed that the metaphoric mappings elaborate correspondences between source and target concepts of idioms and thus facilitate EFL learners to understand the underlying motivations. However, this method has not been implemented in EFL classrooms yet and still begs further investigation.

The present study aims to examine the potential of implementing the method which involves metaphoric mappings in EFL classroom as well as to investigate the effect of EFL leaners' learning idioms. To create a meaningful environment for EFL learners to use idioms, the study was conducted in an English writing class, in which the participants learned idioms for purposes and then used the idioms in meaningful contexts. The results of the study may shed light on the EFL pedagogical developments and material designs.

\section{Methods of Teaching Idioms: Review and Renew}

\subsection{Teaching Idioms as Formulaic Expressions through Memorization}

Idiomatic expressions used to be viewed as formulaic expressions that could only be understood through direct and explicit interpretations. For L2 learners, translation has traditionally been regarded as the most direct way of understanding idiomatic expressions. Reference books are edited to highlight the contrastive studies between the target and the native languages. Example (1) presents a typical arrangement of reference books: common expressions in Chinese are matched to those in English, and are accompanied with Chinese example sentences and the English translations:

(1) (Cheng 2000: 1)

0001 八卦新聞 Yellow journalism

例: 八卦新聞沒什麼教育性和知識性, 可是許多人愛看。

Yellow journalism is hardly educational and informative, but a lot of people love it.

002 巴結 Butter me up

例: 我知道他為什麼巴結我，他想追我姊姊。

I knew why he tried to butter me up; he wants to chase my sister.

For L2 learners, such reference books are resourceful because they can refer to the books to obtain figurative meanings and their translations immediately. However, learning idioms by memorizing them might be time- and effort-consuming, as the idiomatic expressions listed are not associated regarding meanings or themes, and the selection of targeted expressions lacks logical relationships and systems. L2 learners pick up idiomatic expressions as discrete and isolated entities, without systematic arrangements and authentic circumstances; this type of rote learning that may result in short retention of what they have learned is impractical.

\subsection{Teaching Idioms as Metaphors through Awareness-Raising Activities}

To seek logical arrangements of idioms and put them in a more meaningful learning context for L2 learners, researchers (Wingfield 1968; Kövecses \& Szabó 1996) have devoted themselves to looking for certain systematicity in idioms. Wingfield (1968) suggests four broad divisions of English idioms: idioms that present obvious metaphorical sense (e.g., lose one's head, meaning to lose control of temper); idioms that consist of metaphors that are drawn from social and professional activities (e.g., see red, derived from the idea of bullfighting); idioms that have been culture-bound historically (e.g., pay tribute to, meaning to praise or laud, originating from Latin tribütum 'grant'); and idioms that are culture-bound to a specific language community (e.g., on the level, meaning being honest and straightforward in American English). The first two divisions present little communication difficulty owing to the apparent metaphorical senses of metaphors; the third and fourth divisions, however, could be more difficult to comprehend since tracing back and discovering the origins of the idioms could be difficult. He thus claims that the culture-bound idioms could cause the greatest difficulty for L2 learners, in that they are foreign to the cultural background of English.

To breach the cultural boundary created by the lack of equivalent L1 expressions, adopting direct comparisons between L1 and L2 through awareness-raising activities is suggested. For instance, Deignan, Gabry, and Solska (1997) ask Polish learners of English to compare expressions in the two languages and find patterns of translating one language into another. The cross-linguistic comparisons can alert learners to the fact that what exists in L1 does not always exist in L2. Moreover, to overcome the culture-bound problem caused by unfamiliar historical origins, Boers (2001) suggests that EFL teachers raise L2 learners' awareness of etymology through an imagery process. By proposing a simple question such as, "Where might this expression come from?" EFL teachers can encourage L2 learners to hypothesize about the etymological origins of idioms. For example, 
learners could call up an image of a knight in full armor during medieval times when learning the idiom having $a$ chink in one's armor, and an image of sailing when learning the idiom a steady hand on the tiller.

The awareness-raising activities, however, have some limitations. Boers (2001) admits that not all idioms can be easily hypothesized by their etymological origins; some may be too opaque to call up any images, or too frequently used to notice the possible stories behind them. The imagery process may be particularly difficult for L2 learners who do not share a similar cultural and historical background with native speakers of English. The lack of knowledge may either hinder L2 learners' capability in utilizing the imagery process or even mislead them in comprehending idioms.

\subsection{Teaching Idioms as Metaphors through Conceptual Metaphors}

The systematicity in idioms has successfully been probed into from the viewpoint of cognitive linguistics. Researchers (Lakoff \& Johnson 1980; Kövecses \& Szabó 1996) have systematized idioms based on their common concepts. For example, idiomatic expressions such as spark off, snuff out, fan the flame, and do a slow burn all relate to one common concept: fire. The idioms also reflect various aspects of the phenomenon of fire: the beginning (spark off), the end (snuff out), the intensity (fan the flame), and the duration (slow burn). The researchers thus claim that these types of idioms should be regarded as products of a conceptual system rather than simply a matter of language. The idioms are motivated conceptually by general knowledge of the world, which is embodied in the conceptual system (Kövecses \& Szabó 1996); this knowledge entails a systematic structure, which characterizes a corresponding coherent system of the idiomatic expressions (Lakoff \& Johnson 1980). For instance, the fire-related idioms can be used to describe the emotion anger correspondingly:

\section{(2) Source concept: FIRE Target concept: ANGER}

The fire is anger.

The thing burning is the angry person.

The intensity of fire is the intensity of the anger.

The duration of fire is the duration of being angry.

In this case, the idioms are considered to be motivated rather than arbitrary. The connection between two concepts, or called conceptual metaphor (Lakoff 1986), illustrates the metaphoric connection between fire and anger. L2 learners can make sense of the meanings of idioms through their awareness and knowledge of the conceptual metaphors behind them.

The idea of implementing conceptual metaphors when teaching idioms has been proved beneficial in helping learners recognize the systematicity between two concepts, and hence improves meaning comprehension (Kömür \& Çimen 2009), as well as extends retention of the expressions learned (Boers 2000). The findings suggest that idiomatic expressions presented to L2 learners should be grouped with conceptual metaphors, as can be illustrated in (3):

(3) (Modified based on Boers 2000)

English has many expressions to describe anger. Some of them are very common, such as, She is angry. He's mad at you. Other expressions can be used to specify a type of anger:

\section{ANGER IS A HOT FLUID IN A CONTAINER}

Anger welled up inside me.

I am boiling with anger.

She was all steamed up.

\section{ANGER AS FIRE}

She was breathing fire.

He's hot under the collar.

She added fuel to the fire.

However, potential problems might still be foreseen in an EFL context; a possible scenario is when EFL learners fail to recognize the underlying structures that are coherent to the target concepts. For example, the idioms have a short fuse, blow off some steam, and blow up are listed under the source concept explosion and are mapped to the target concept anger; however, it is hard to discern the systematicity and relations between explosion and anger based on the three idioms. Thus, EFL learners might have a hard time perceiving the conceptual metaphors, 
and they might not be able to recognize these conceptual metaphors in other contexts. Research conducted in EFL context (Chen \& Lai, in press) also proves that EFL learners have a hard time comprehending metaphor-based expressions whose conceptual metaphors were distinct from their native language.

\subsection{Effective Complements in Teaching Idioms}

To facilitate L2 learners to establish associations between concepts, it is recommended that materials concerning metaphoric mappings should be integrated into textbook designs. Metaphoric mappings represent the processes that illustrate, as well as elaborate, the associating relations between the source and the target concepts. There are two types of mapping processes: ontological mappings characterize the correspondences between basic constituent elements in the source concept and in the target concept. Example (2) shows the ontological mappings of the conceptual metaphor ANGER IS FIRE. The other type of mapping process, epistemic mappings, elaborates on the knowledge of the concepts and draws on more detailed but complex correspondences. For instance, the conceptual metaphor ANGER IS FIRE encompasses the epistemic mappings as shown below in (4):

(4) (Lakoff 1986:20)

Source: Things can burn at a low intensity for a long time and then burst into flame.

Target: People can be angry at a low intensity for a long time and then suddenly become extremely angry.

Source: Fires are dangerous to things nearby.

Target: Angry people are dangerous to other people.

In addition to schematizing the structures of both source and target concepts, metaphoric mappings are believed to be useful in bridging the gap between cultural differences. Kövecses (2001) proposes an idea and explains the process in examining English and Hungarian idioms. If both L1 and L2 have similar conceptual metaphors, ontological mappings may help learners to create links between the distinct linguistic expressions of the two languages. For example, in the case of the conceptual metaphor ANGER IS FIRE, English spit fire corresponds to Hungarian tüzet hány 'vomit fire'; therefore, the schematic knowledge of FIRE can help learners to match the meaning of hány with spit and infer meanings of the two expressions. On the other hand, if two languages have different conceptual metaphors, or if one has a conceptual metaphor that does not exist in the other language, epistemic mappings can carry over knowledge about elements in the source domain onto elements in the target domain, helping learners to relate their knowledge of the used and abstract half to the unused and concrete half. The example given by Kövecses (2001) is stated in (5):

(5) (Epistemic mapping process of Hungarian speakers learning English idioms)

English: Wet blanket

ENTHUSIASM IS FIRE: causing fire to end $\rightarrow$ causing states to end

Hungarian: ünneprontó ('festivity-breaker')

STATES ARE FUNCTIONAL OBJECTS: causing objects not to function

$\rightarrow$ causing states to end

The mapping process:

Hungaran ünneprontó $\rightarrow$ causing states to end $\rightarrow \quad$ causing fire to end $\rightarrow$ English Wet blanket

\section{A Case Study}

Metaphoric mappings are considered beneficial to L2 learners, since the mappings help learners to construct the correspondences between two concepts and encourage them to associate existing and universal knowledge with unfamiliar and specific knowledge. the However, as also admitted by Kövecses (2001), the effect of using metaphoric mappings in teaching idioms in an EFL context requires additional empirical evidence and practical implementations. To examine the potential of this method, a small-scale study was conducted.

\subsection{Participants and Backgruond Information of the Research Site}

The study was conducted in a writing classroom with 19 university students in Taiwan. The students were in their sophomore, junior, and senior years. They were from different colleges, such as the College of Social Sciences, the College of Commerce, the College of Communication, and the College of Foreign Languages; however, none of them majored in English. They were Chinese native speakers and had spent at least seven years learning English in junior and senior high school. To determine their general English proficiency, they were given a TOEIC full-length non-official simulated test; the scores of the test indicated that their English proficiency was at the intermediate to high-intermediate level. 
The class was a one-semester selective course offered by the Foreign Language Center of the university. The goal was to provide learning opportunities to students who want to improve their English writing abilities, and to familiarize the students with English writing styles for academic pruposes. The course was organized based on different genre types, including descriptive, narrative, exploratory, and argumentative essays. The instructor, who was also the researcher, had been offering this course for six times in three successive years; she was experienced in teaching English writing for academic purposes and was familiar with general background of students in this university.

\subsection{Teaching Method and Procedures}

This experiment was carried out while the course proceeded to practice descriptive and narrative essay writing. The instructor, from her previous experience of teaching this course, found these two types of genre particularly difficult for EFL students due to their lack of vocabulary and incapability of making up descriptions. For example, when describing their favorite food, EFL students tended to use general and short adjectives, such as delicious and yummy; when describing their feelings of eating the food, they used common adjective like happy and great. They rarely adopted strategies like making comparisons or analogies when trying to describe subjects. The situation also applied to the the EFL students' narrative essay writings. When they narrated a story, either they offered very few and imprecise descriptions of story characters and background, or they wrote lengthy and vague sentences trying to depict simple objects. The instructor thus felt the urge and need to help students use English language more effectively and efficiently.

In class, the instructor asked the students to write a three- to four-paragraph essay describing an experience of being extremely angry. After submitting the first draft, the students were introduced to the concept of metaphors and conceptual metaphor. Two-page handout were distributed in class as the teaching materials (see Appendix A); the content, including a few idioms as examples, were modified based on Boers' (2000) study, and the samples of metaphoric mappings were collected from Lakoff's (1987) analysis. To illustrate the concept of conceptual metaphor, a short article about issues of emotion controls was given on the first page of the handout; the students were asked to read over the article and to circle the idiomatic expressions used in it. The instructor then led the students to think about general metaphoric themes of the idiomatic expressions, and to draw linking diagrams for expressions which belonged to the same metaphoric themes. In the meantime, the instructor explained to the students that the linking diagrams were the logical mappings for the metaphors (i.e., metaphoric mappings). The instructor then directed the students to complete the exercise on the second page of the handout: to create metaphoric mappings for the idiomatic expressions of anger. The handouts were collected back to the instructor after the students completed the exercise.

In the end of the class, the students were told to revise their first draft at home, and were encouraged to integrate as many idiomatic expressions as possible. They submitted both the original and the revised essays a week later. The essays were then analyzed by the instructor, who was also the researcher, to investigate how the students used idiomatic expressions as well as to measure the effects of the new cognitive-oriented teaching method. The essays were first typed into computer and were saved as text files. A concordance program AntConc was used for the preliminary analysis, including computing for total number of words and sentences, and sorting key words related to conceptual metaphors of anger. Key words like fire, heat, explode were used. Later on, the researcher reviewed the essays one by one in order to look for expressions which were used to describe anger but were left out in the privoise process owing to imprecise keyword search. All the expressions used to describe anger, no matter they were fixed idioms or creative analogies, were listed and were categorized based on conceptual metaphors; the frequencies of learners' uses of idioms were then calculated manually.

\subsection{Results and Discussion}

The participants' essays were analyzed in order to analyze anger idiom uses. The results show that the students tended to use idioms of the conceptual metaphor ANGER IS FIRE more frequently than idioms of the conceptual metaphor ANGER IS HEAT FLUID IN A CONTAINER. Out of 486 sentences from the 19 essays, 25 sentences contained idiomatic expressions for anger that were derived from ANGER IS FIRE, such as, "That kindled my fire" or "What added the fuel to the fire was that two suspects were jumping happily on my bed." On the other hand, 19 sentences contained idiomatic expressions for anger that were derived from ANGER IS HEAT FLUID IN A CONTAINER, such as "My anger was boiling, which was going to explode" or "Eventually, I couldn't simmer down."

The differences regarding frequencies of uses may have resulted from the differences between Chinese and English cultures. Chinese also has idioms derived from the ANGER IS FIRE metaphor, such as huǒ-shàng-jiā-yóu (fire-on-add-oil 'add fuel to the fire') and huǒ-mào-sān-zhàng (fire-rise-three-zhang 
'fire/anger is flaming up as high as ten meters'). However, rather than using the concept of fluid to describe anger, Chinese uses the concept of $q i$ ('gas'), as in the conceptual metaphor ANGER IS THE HOT GAS IN A CONTAINER. For instance, Chinese expressions like shēng-mēn-qì (produce-contained-gas 'feeling sulky') and $n \grave{u}$-qì-chōng-chōng (angry-gas-soar-soar 'in a state of fury') adop the concept of qi ('gas'). Qi is a substance that functions as a motivating power for the human body, and it is an indispensible element in traditional Chinese medicine. In the theory of yin-yang, fluid and gas belong to opposite categories. Chinese speakers are used to the GAS metaphor in Chinese; thus, when learning English, Chinese L2 learners show a tendency to incorporate the GAS metaphor rather than the FLUID metaphor. The other evidence of the participants' awareness of cultural differences is that they used more idioms of the shared conceptual metaphor ANGER IS FIRE than idioms of the unfamiliar and culture-specific conceptual metaphor ANGER IS HEAT FLUID IN A CONTAINER. The selection of one conceptual metaphor over the other was determined by the underlying cultural models (Yu 1998).

Moreover, some idiomatic expressions of different conceptual metaphors were mixed. For example, in the sentence "I simmered down, but I saw the smoke was pouring out of his ear", the writer used both the ANGER IS HEAT FLUID IN A CONTAINER metaphor ("simmer down") and the ANGER IS FIRE metaphor ("smoke is pouring out of the ears"). The reason may be that fluid and fire are dependent on each other naturally: fluid evaporates into vapor or gas when heated, while vapor liquefies when cooled. Therefore, when using metaphoric mappings in understanding two conceptual metaphors, the participants may easily relate them together due to their dialectical nature (Yu 1998). The mixed expressions also reveal the phenomenon that the participants were schematizing the concepts when producing idiomatic expressions.

In short, the study is an investigation of the potential pedagogical implements of using metaphoric mappings in teaching English idioms to L2 learners. Though the study does not follow a strict experimental control, and the results might not be generalized, the findings from the participants' writings are still promising for EFL teacher to teach English idiomatic expressions in class.

\section{Implications and Conclusions}

The present study reviews the history and development of idiom-teaching methods in the EFL contexts. The pedagogies are changed over time along with the changes of definitions of idioms given by linguists. Cognitive linguists treat such expressions as presentations of the process of cognitive operations, the process in which not only linguistic knowledge but also world knowledge are involved. For EFL learners who lack exposure to the target language and culture, to acquire English idioms means to learn both language and cultural conventions. Therefore, the suggested teaching method gives considerations to both language and culture, and provides EFL learners with dependable clues in comprehending and learning idiomatic expressions.

Futhermore, the role of EFL teachers is not only important but also indispensable. For one thing, awareness of conceptual metaphors does not guarantee L2 learners' automatic access to conceptual metaphors as well as their active computation of metaphoric mappings during idiom processing (Gibbs, Bogdanovich, Skyes, \& Barr 1997); L2 learners still need instructions to assist them in relating their knowledge and experiences of the conceptual metaphors precisely and in schematizing concepts properly at the initial stage. Second, L2 learners need explicit instructions that point out differences between cultures and languages in order to avoid miscomprehension or overgeneralization. In the EFL environment that has no direct contact with the target language, the main source of feedback regarding correction comes from EFL teachers.

Finally, the fact that not every idiom is metaphorically interpretable should be made clear to L2 learners. Methods incorporating awareness-raising activities, conceptual metaphors, and metaphoric mappings could assist learners in comprehending and systemizing idioms as metaphors; however, the traditional method should not be abandoned completely. EFL teachers should lead L2 learners to use suitable methods to acquire English idioms in an effective and efficient manner.

\section{References}

Boers, F. (2000). Metaphor awareness and vocabulary retention. Applied Linguistics, $21(4), 553-571$. http://dx.doi.org/10.1093/applin/21.4.553

Boers, F. (2001). Remembering figurative idioms by hypothesising about their origins. Prospect, 16(3), 35-43.

Chen, Y., \& Lai, H. (In Press). The Influence of Cultural Universality and Specificity on EFL Learners' Comprehension of Metaphor and Metonymy. International Journal of Applied Linguistics. http://dx.doi.org/10.1111/ijal.12021

Cheng, K. (2000). Chinese Equivalents to English Idioms. Taipei: Hwatai Publisher. 
Cooper, T. C. (1999). Processing of idioms by L2 learners of English. TESOL Quarterly, 33(2), 233-262. http://dx.doi.org/10.2307/3587719

Deignan, A., Gabrys, D., \& Solska, A. (1997). Teaching English metaphors using cross-linguistic awareness-raising activities. ELT Journal, 51(4), 352-60. http://dx.doi.org/10.1093/elt/51.4.352

Gibbs, R. W., Bogdanovich, J. M., Skyes, J. R., \& Barr, D. J. (1997). Metaphor in idiom comprehension. Journal of Memory and Language, 37(2), 141-154. http://dx.doi.org/10.1006/jmla.1996.2506

Kövecses, Z., \& Szabó, P. (1996). Idioms: A view from cognitive semantics. Applied Linguistics, 17(3), 326-355. http://dx.doi.org/10.1093/applin/17.3.326

Kövecses, Z. (2001). A cognitive linguistic view of learning idioms in an FLT context. In M. Pütz, S. Niemeier, \& R. Dirven (Eds.), Applied cognitive linguistics II: Language pedagogy (pp. 87-115). Berlin: Mouton de Gruyter.

Kömür, S., \& Çimen, S. S. (2009). Using conceptual metaphors in teaching idioms in a foreign language context. Sosyal Bilimler Enstitüsü Dergisi (íLKE) [Journal of the Institute of Social Sciences (Policy)], 23, 205-222. Retrieved April 8, from http://akademik.mu.edu.tr/data/06020000/resim/file/23-12-\%C3\%85_evki\%20K\%C3\%83\%C2\%B6m\%C3 $\% 83 \% \mathrm{C} 2 \% \mathrm{BCr}, \% 20 \% \mathrm{C} 3 \% 85$ _eyda $\% 20$ Selen $\% 20 \% \mathrm{C} 3 \% 83$ imen.pdf

Lakoff, G. (1987). Woman, fire, and dangerous thing: What categories reveal about the mind. Chicago, London: University of Chicago Press.

Lakoff, G., \& Johnson, M. (1980). Metaphors we live by. Chicago: University of Chicago Press.

Nandy, M. (1994). English expressions with idioms, prepositions and metaphors. Kuala Lumpur, Malaysia: S. Abdul Majeed \& Co.

Wingfield. R. J. (1968). English idiom in a second language teaching situation. ELT Journal, 22(3), 231-234. http://dx.doi.org/10.1093/elt/XXII.3.231

Yu, N. (1998). The contemporary theory of metaphor: A perspective from Chinese. Amsterdam: J Benjamins.

\section{Appendix 1.}

Handouts for the Case Study

\section{Metaphor-Make Language Lively}

\section{Read the following article. Identify and circle metaphors used in it (including words, phrases \& idioms).}

\section{Managing the Emotions}

People manage their emotions in different ways, depending on their personality and the culture they live in. In western culture, for instance, crying is usually seen as a sign of weakness, especially for men. Research has shown, however, that crying it out makes people feel better. So perhaps we should encourage our children to wear their hearts on their sleeves more often. It has become a widely accepted idea that, instead of bottling up the emotions, one should ventitiate one's emotions once in a while. One should blow off steam in order to avoid sudden explosions.

However, one emotion may prove to be an exception: anger. In fact, ventilating anger is one of the worst ways to cool down: outbursts of rage typically pump up the arousal, leaving people feeling more angry, not less. When people blow up at the person who has provoked their anger, their rage not only peaks during the outbursts, but the angry mood is also prolonged. After reaching their boiling point, these people keep fuming much longer.

A far more effective way of managing anger is to simmer down first, and then, in a more constructive manner, confront the person to settle a dispute. Imagine that someone pushes you aside in a crowd. Your first thought may be "How rude!" That reflex may then be followed by more negative thoughts: "He could have hurt me! I can't let him get away with that." Then, if someone else behind you bump into you because you have slowed down, you are apt to erupt in rage at that person too. Now imagine a more positive line of thought toward the man who pushed you aside: "Maybe he had a good reason, such as an emergency." Your may be cool down by thinking like this, and could dismiss the anger with a laugh. 


\section{Exercise 2}

English has a lot of expressions to describe emotions. Take anger for example. Some of these are very common: she's angry. He's mad at you. To make your language more varied, other expressions can be used to specify the kind of anger.

Following are 15 expressions. Think about the corresponding characteristics and relationships between anger and comparable concepts, and briefly write down these relationships.

Anger is fire.

If you add fuel to the fire, the fire will rise up and become stronger. $\rightarrow$ add fuel to the fire = make angry person much angrier!
What he said added fuel to the fire.

He made an inflammatory remark.

He was hot under the collar.

She was breathing fire.

She exploded.

Anger is the hot fluid in a container.

She is all steamed up.

I am boiling with anger.

She flipped her lid.

She blew up at me.

Simmer down.

Angry people are dangerous animals.

He has a ferocious temper.

He unleashed his anger.

Don't snap at me.

Don't bite my heat off.

He was breathing fire. 